\title{
Optimizing energy harvesting for foot based wearable sensors
}

DOI:

10.1109/EMBC.2018.8512476

\section{Document Version}

Accepted author manuscript

Link to publication record in Manchester Research Explorer

\section{Citation for published version (APA):}

Beach, C., Green, P., \& Casson, A. (2018). Optimizing energy harvesting for foot based wearable sensors. In IEEE EMBC https://doi.org/10.1109/EMBC.2018.8512476

\section{Published in:}

IEEE EMBC

\section{Citing this paper}

Please note that where the full-text provided on Manchester Research Explorer is the Author Accepted Manuscript or Proof version this may differ from the final Published version. If citing, it is advised that you check and use the publisher's definitive version.

\section{General rights}

Copyright and moral rights for the publications made accessible in the Research Explorer are retained by the authors and/or other copyright owners and it is a condition of accessing publications that users recognise and abide by the legal requirements associated with these rights.

\section{Takedown policy}

If you believe that this document breaches copyright please refer to the University of Manchester's Takedown Procedures [http://man.ac.uk/04Y6Bo] or contact uml.scholarlycommunications@manchester.ac.uk providing relevant details, so we can investigate your claim.

\section{OPEN ACCESS}




\title{
Optimizing energy harvesting for foot based wearable sensors
}

\author{
Christopher Beach, Student Member, IEEE, Peter R. Green, Member, IEEE, \\ and Alexander J. Casson, Senior Member, IEEE
}

\begin{abstract}
Wearable devices have the potential to improve healthcare, but suffer from significant barriers to adoption, including the need for constant recharging. Harvesting energy from the ambient environment to top-up batteries can overcome this, but the actual energy available is very small, and hence it is critical that the whole system is highly optimized. This paper presents an investigation into the optimization of inertial energy harvesters for placement at the human foot. Lower body locations have previously been shown to be very energy dense, however previous energy harvester modeling has focused on the lower leg rather than the foot itself for ease of device placement. We show that the typical energy density can be almost double at the foot compared with lower leg positions, with substantially more energy concentrated in a smaller bandwidth. There is thus a dual benefit of placing a harvester at the foot: there is more energy due to the larger movement of the foot, and more efficient (higher $Q$ ) harvesters can be used to increase the collected energy. We place these results in context by analyzing the power demands of a typical wearable, and identify that with appropriate harvester tuning the peak current requirements of the electronics can be fitted into the energy peaks generated from each footstep.
\end{abstract}

\section{INTRODUCTION}

Wearable devices offer many promises to transform healthcare and improve the quality of life for people worldwide. With the increasing accuracy of these devices they offer the potential to provide out-of-the-clinic care where patients can ultimately be monitored and treated in their own home, without the need for intervention from a medical professional [1]. This can be advantageous in reducing costs for healthcare providers, and keeping people out of hospital environments. In spite of the promised benefits, recent wearable devices are still limited in how user friendly they are [2], as well as their social-acceptability [3]. This can limit their adoption, especially amongst the elderly, who may be technically illiterate and are the least likely to use a wearable device [4]. A significant barrier to adoption remains the need to charge devices on a near daily basis [5], [6]. With this in mind, medical wearables should ideally be fully energy autonomous through techniques such as energy harvesting where energy is collected from the ambient environment to extend battery life.

As a result, using energy harvesting to power wearables has gained significant interest recently, with a comprehensive

This work was in part supported by the UK Engineering and Physical Sciences Research Council grant number EP/M507969/1 and the Doctoral Training Partnership with the University of Manchester.

C. Beach, P. R. Green and A. J. Casson are with the School of Electrical and Electronic Engineering, The University of Manchester, UK. Email: \{christopher.beach, p.r.green, alex.casson\}@manchester.ac.uk review given in [7]. In particular, large amounts of energy can be harvested from the lower body. Examples of harvesting done in the lower body include [8] which describes an energy harvesting system that can extract energy from each time the wearer's foot strikes the floor by means of an air bladder pumping air into a turbine with each footstep. [9] utilized a piezoelectric element that flexes with each step, generating on average $8.4 \mathrm{~mW}$ at a walking pace. Despite this potential, current wearables are mainly located at the wrist due to the ability to sense motion, heart rate, temperature, and sweat in a socially-acceptable form factor as many people are used to wearing a watch. Work is ongoing to allow the monitoring of more bio-signals, such as heart rate [10] and gait [11], at the foot and lower body locations where they can benefit from the much larger potential for energy harvesting, in addition to meeting the social-acceptability requirements as devices can be hidden in a shoe.

In this paper we investigate the optimization of inertial energy harvesters for placement at the human foot. We use accelerometers placed on the body to estimate the energy available at different locations. Similar modeling has been done before, using the lower leg as a proxy for the foot, assuming the two are the same. By placing accelerometers on both the lower leg and the foot we show that this is not the case. We show for the first time that substantially more energy is available from the foot compared to the lower leg, with a very different frequency content allowing the $Q$ factor of the energy harvester to be further optimized. In addition, we compare the quasi-periodic energy generation that can be obtained at the foot during each footfall to the typical energy demands of a modern wearable, which is limited not by average current draw, but by the peak current requirements of a wireless radio. We show that with suitable optimization the energy required for each packet transmission is within the energy generated by each footfall, potentially allowing a reduction in energy storage requirements. Finally, we have made the modeling in this paper freely available as a MATLAB GUI to help others design more optimized shoe based energy harvesters. The remainder of this paper is organized as follows. In Section II we present the methods used to model the harvester and collect sample input data. Section III presents the results from the harvester model, comparing the foot and lower leg sites as well as the energy requirements of a typical Bluetooth Low Energy wireless radio. Finally conclusions are drawn in Section IV. 


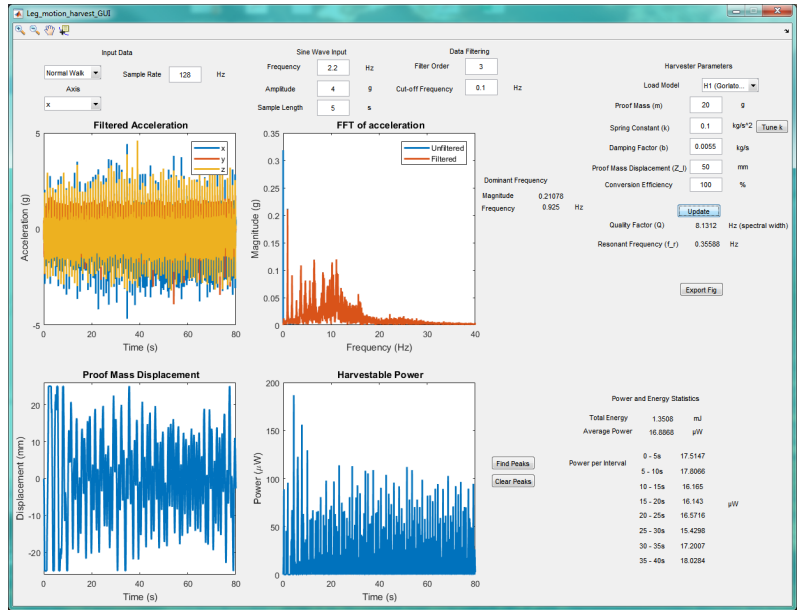

Fig. 1. Screenshot of the energy harvester GUI.

\section{METHODS}

\section{A. Harvester model}

Our MATLAB GUI tool for modeling an intertial energy harvester and storage device is shown in Fig. 1. It allows the user to load a dataset of accelerometer data and to modify the harvester parameters to identify the power waveforms from this harvester. We have made this GUI and dataset available as a free download (https://github.com/ CASSON-LAB) to help designers specify the energy budgets of their wearable devices.

To identify the typical amount of energy available from human movements, a model of an inertial energy harvester was created, based upon a design from [12] which assumes that the energy harvester is a damped-mass-spring system. To ensure that we do not overestimate the amount of energy available, we only look at the energy in one axis, the one with the largest magnitude. Other models take the magnitude of all three axes, which gives larger output values. Additionally, calculating the magnitude is a non-linear operation that will affect the frequency content of the data.

The movement of the proof mass in the harvester is found by using the approximation given in [12], which describes a second order band pass filter with a quality factor $Q$ and resonant frequency $f_{r}$. This is shown in (1), which gives the displacement over time, $z(t)$, of the moving mass, where $Q=\frac{\sqrt{k m}}{b}, f_{r}=\frac{\sqrt{k / m}}{2 \pi}, a$ is the measured acceleration, $b$ the harvester damping factor, $m$ is the proof mass, and $k$ is the spring constant. This is consistent with the modeling and notation in [12]. To optimize the harvester performance, the resonant frequency can be tuned to match the fundamental frequency of the input data, which can automatically be done in the GUI. Finally, the movement of the proof-mass can be converted into a power waveform using (2). An efficiency factor can also be factored in to account for any losses in the transduction method and the connected power electronics. However in this work we assume these efficiencies to be $100 \%$.

$$
z(t)=\mathcal{L}^{-1}\left\{\frac{a(s)}{s^{2}+\left(2 \pi f_{r} / Q\right) s+\left(2 \pi f_{r}\right)^{2}}\right\}
$$

$$
P(t)=b\left(\frac{d z(t)}{d t}\right)^{2}
$$

The power available from an energy harvester is not the constant voltage or current which is required by the attached electronic circuitry. Instead the power output consists of narrow, large amplitude peaks that correspond to each footstep of the wearer. For this reason, harvesters are paired with storage elements, typically supercapacitors, which ensure a constant voltage can still be supplied to the electronic circuitry. Supercapacitors suffer from self-discharge, and it can not be guaranteed that the necessary energy will be available when it is required.

\section{B. Analysis methods}

To estimate the amount of energy that can be collected from the foot compared to the lower leg, we have collected five records from a subject walking on a treadmill at three speeds: $1.0,3.5$ and $6.5 \mathrm{~km} / \mathrm{h}$, which are referred to as slow walk, normal walk and light jog respectively. Acceleration data was collected using Axivity AX3 sensors, which were attached to two sites on the subject, the lower leg and the foot. Both sensors were orientated in the same direction with the $\mathrm{x}$-axis horizontal (pointing forward), the $\mathrm{y}$-axis vertical (pointing down) and the z-axis horizontal (pointing away from the leg). The sensor was set to $\log$ data at $100 \mathrm{~Hz}$ for a total of 6 minutes, allowing 2 minutes for each speed. Prior to data analysis the data was upsampled to $128 \mathrm{~Hz}$ and filtered with a 3rd order low pass filter with a cut-off of $0.1 \mathrm{~Hz}$ to remove the gravity component in the acceleration. Experimental procedures were approved by the University Research Ethics Committee at the University of Manchester.

To place the results in context we also analyze the power draw of typical electronic parts that make up a wearable. These constituent parts are: a sensing element (e.g. an accelerometer); signal conditioning (eg. amplifiers and filters); a micro-controller; and a wireless radio, (eg. a Bluetooth Low Energy (BLE) device). The first two of these devices can be characterized as having a quiescent current draw which is relatively constant. The micro-controller and radio have much more peaky power draws, as they spend most of their time in sleep mode, only waking intermittently to collect or transmit data. The device with the largest ratio between on and sleep modes is the wireless radio [13]. As the wireless radio typically dominates the power draw, we only compare the power draw of this device against the power available from the harvester. We measure the current draw of a Nordic nRF52 BLE radio [14] which requires $20 \mathrm{~mW}$ of power for $0.3 \mathrm{~ms}$ for a receive or transmit operation of a 27 byte payload. Potentially, if the BLE radio did not have to run on demand, this peak current draw could be fitted into the peaks of energy available from the energy harvester with each footfall. The dimensions of these harvester peaks are well defined and relatively predictable when harvesting at the foot, and doing this would allow the losses of the storage element to be overcome, with the energy being utilized as soon as it is available. 


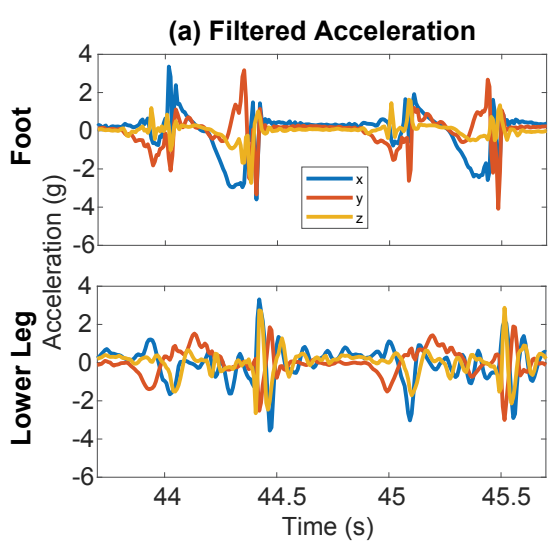

(b) Proof Mass Displacement

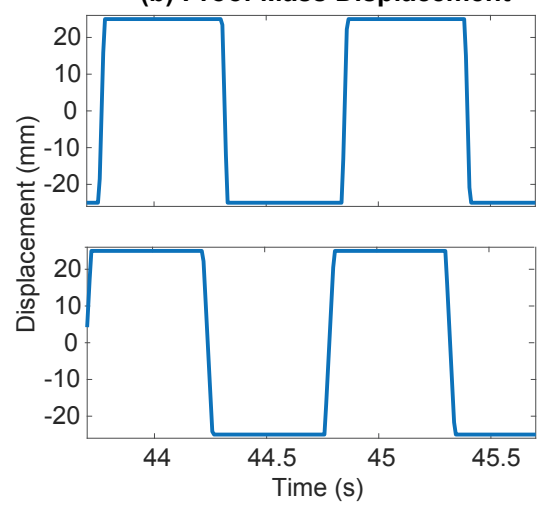

(c) Harvestable Power

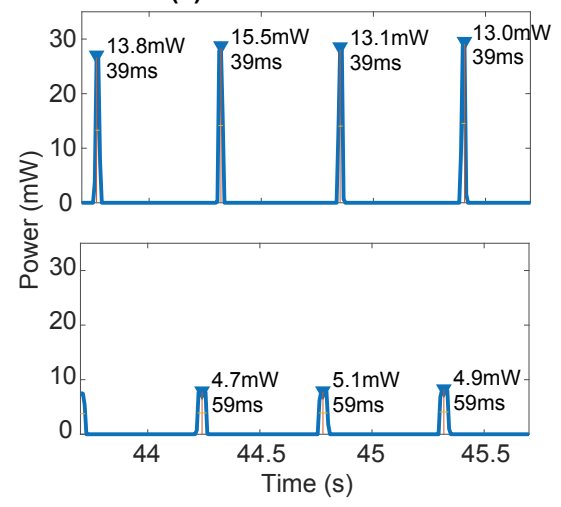

Fig. 2. Example data from the foot (top) and lower leg (bottom) showing input acceleration data, proof mass displacement, and output power during a normal walk at $3.5 \mathrm{~km} / \mathrm{h}$. Annotations in (c) indicate the duration and average power in each peak.

TABLE I

MEAN FIGURES FROM THE 5 RECORDS WITH THE ENERGY HARVESTER IN FOOT AND LOWER LEG LOCATIONS, USING THE HARVESTER PARAMETERS Listed IN SECTION III-A. HARVESTER PARAMETERS (PARTICUlarly $Q$ FACTOR) ARE THE SAME FOR ALl CASES.

\begin{tabular}{cc|cccc|ccc}
\hline Location & Activity & $\begin{array}{c}\text { Avg. power } \\
(\mu \mathrm{W})\end{array}$ & $\begin{array}{c}\text { Avg. power } \\
\text { in peak }(\mathrm{mW})\end{array}$ & $\begin{array}{c}\text { Duration of } \\
\text { avg. peak } \\
(\mathrm{ms})\end{array}$ & $\begin{array}{c}\text { Energy in } \\
\text { avg. peak } \\
(\mu \mathrm{J})\end{array}$ & $\begin{array}{c}\text { Fundamental } \\
\text { magnitude } \\
(\mathrm{W} / \sqrt{(\mathrm{Hz})})\end{array}$ & $\begin{array}{c}\text { Fundamental } \\
\text { frequency } \\
(\mathrm{Hz})\end{array}$ & $\begin{array}{c}\text { Percentage of } \\
\text { power in } \\
\text { fundamental }\end{array}$ \\
\hline \multirow{3}{*}{ Foot } & Slow walk & $048 \pm 16.6$ & 00095 & 322 & 031 & 0.105 & 0.515 \\
& Normal walk & $899 \pm 25.1$ & 12620 & 039 & 497 & 0.473 & 0.925 & 3.46 \\
& Light jog & $207 \pm 3.90$ & 00536 & 174 & 093 & 0.920 & 1.329 & 5.51 \\
\hline \multirow{2}{*}{ Lower leg } & Slow walk & $071 \pm 30.58$ & 00209 & 308 & 065 & 0.123 & 0.515 & 3.28 \\
& Normal walk & $541 \pm 23.16$ & 05537 & 057 & 315 & 0.279 & 0.925 \\
& Light jog & $096 \pm 3.93$ & 00120 & 316 & 038 & 0.538 & 1.329 \\
\hline
\end{tabular}

\section{RESULTS}

\section{A. Harvester energy}

The harvester model allows modification and exploration of the harvester parameters. The results in this section show one example case, with the parameters set to $m=20 \mathrm{~g}$, $k=0.67557 \frac{\mathrm{kg}}{\mathrm{s}^{2}}, b=0.0055 \frac{\mathrm{kg}}{\mathrm{s}}$ and $Z_{l}=50 \mathrm{~mm}$ to match typical values from the literature. These give the harvester a $Q$ factor of 21.1 and a resonant frequency of $0.925 \mathrm{~Hz}$. Here we analyze the x-axis of acceleration. A sample of the output from the harvester model is shown in Fig. 2, with normal walk data. The quasi-periodic nature of the energy generation is seen, together with the substantially higher power generation from the foot compared to the lower leg.

Each of the five records were processed and the mean of these results are given in Table I. In the normal walk and light jog cases there is more energy available at the foot than the lower leg, as much as 1.6 times as much in the normal walk case. Additionally, the peak power in both of these cases is higher at the foot than the lower leg, almost 2.3 times as much in the normal walk case. The duration of each peak is shorter in both cases, although the total energy harvested is still higher at the foot location. In the slow walk case this scenario is reversed. The average power of the waveform is 1.5 times lower on the foot than the lower leg in the slow walk case, and both the average power and duration of a peak is lower at the foot site.

The data presented in the last three columns of Table I summarizes the frequency content in each of the cases. While the fundamental frequency experienced at the foot and lower leg is the same, the magnitude of this, and the amount of power in the fundamental, differs substantially between the foot and lower leg. At the foot site, there is always a larger amount power in the fundamental compared with the lower leg. This helps suggest why there is more power available at the foot than at the lower leg in the normal walk and light jog cases. In contrast, in the slow walk case the fundamental has a larger magnitude at the lower leg than the foot.

An example Fourier transform of accelerometer data from one record is is shown in Fig. 3. From Fig. 3 the distribution of energy amongst the harmonics for each site and speed can be seen. Of note is that at the foot the majority of the energy is spread between the first four, three and two harmonics in each of the slow walk, normal walk and light jog cases respectively. In contrast, at the lower leg site, the energy is much more widely spread across the spectrum. This allows further optimization of foot based harvesters, as not only is there more energy available at the foot in most scenarios, but the energy is more concentrated in lower harmonics. This means harvester designers can use higher $Q$ factors when at the foot, as more energy is available in a narrower bandwidth. This suggests that even more energy than suggested in Table I could be harvested, as in this case both harvesters had the same $Q$ factors. From our new data it is clear that using the lower leg as a proxy site for the foot is not accurate, unlike previously suggested in some literature. 

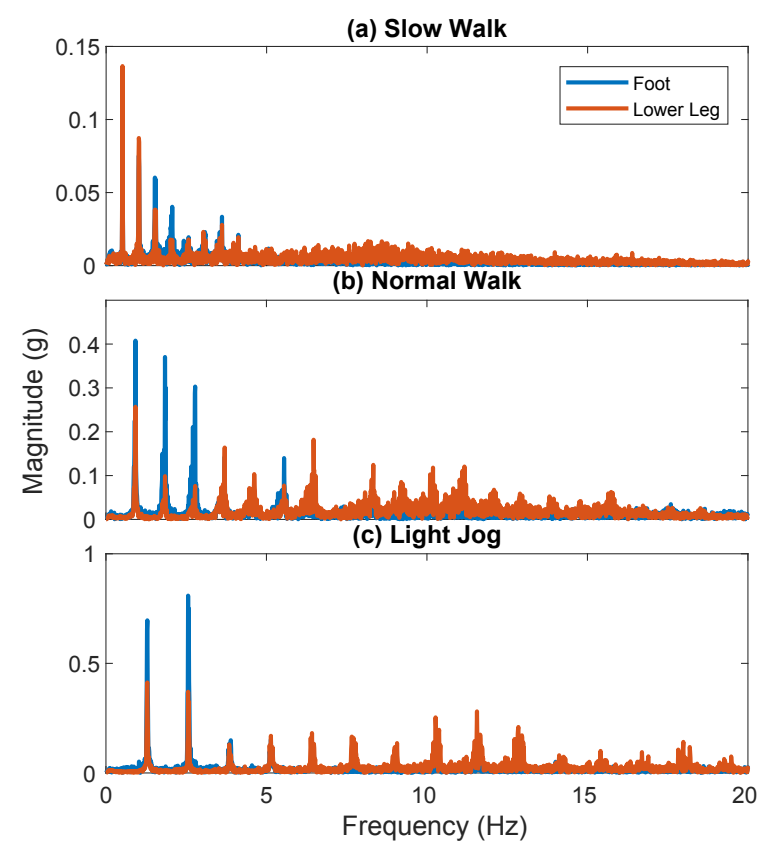

Fig. 3. Fourier transform of the input acceleration data for one record with the accelerometer placed on the foot and the lower leg.

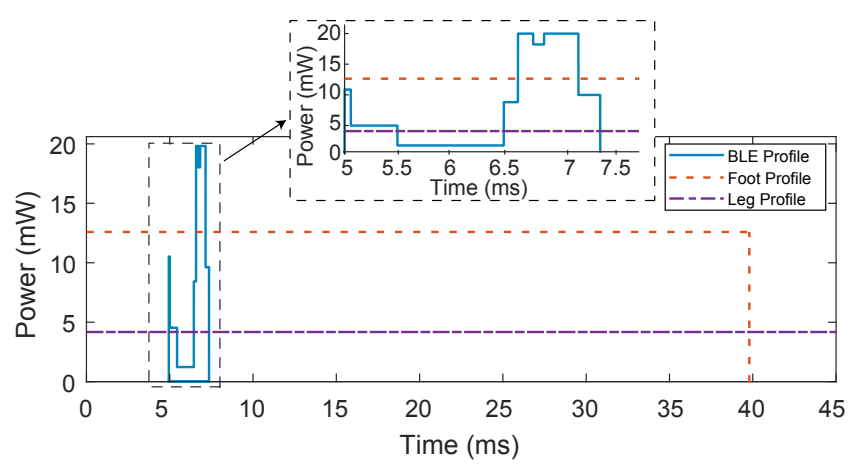

Fig. 4. Power profile of a BLE packet and a footstep, with the harvester placed on the lower leg and on the foot. Note that foot power profile lasts for around $40 \mathrm{~ms}$, while the lower leg profile continues off scale.

\section{B. Fitting with wearable energy requirements}

In order to identify whether the demanding power draw of a wireless radio can fit within the power profile generated from each footstep, the profile of sending of full (27 byte) BLE packet on the nRF52 is shown overlaid against an average power profile generated from a footstep in Fig. 4. This is given using the same harvester parameters as in Section III-A. With these harvester parameters, while the overall energy is sufficient, the peak requirements to are too large to fit into the power profile of a footstep. With further $Q$ tuning, suggested by the results in Fig. 3, the peak power could be increased to allow this. While the widths of the peaks generated are narrower at the foot, it is the peak value, not the duration that creates a limiting factor. We see this as the key next step for foot energy harvesters, it is not about just increasing the average power, but generating energy peaks that are capable of accommodating the high peak currents. Exploiting this would allow a reduction in the size of the energy storage element, reducing size and weight. This will also reduce the losses experienced from the storage element as the energy can be used soon after it is generated.

\section{CONCLUSIONS}

We have investigated the optimization of energy harvesting for wearable sensors and shown that over twice the amount of energy is available for harvesting at the foot compared to the leg. Further, the acceleration at the foot is concentrated in a narrower bandwidth, which means that more efficient, higher $Q$ factor harvesters can be used at this site, further increasing the amount of power available. This potentially allows the peak power draw from a wearable, due to a BLE radio, to be fitted into the peak of energy harvested from each footstep, helping reduce energy storage losses. Implementing this in practice is challenging, and in future work we will discuss aligning wireless transmissions with when these peaks arrive to reduce self-discharge.

\section{REFERENCES}

[1] L. Piwek, D. A. Ellis, S. Andrews, et al., "The rise of consumer health wearables: Promises and barriers," PLoS Med, vol. 13, no. 2, 2016.

[2] J. S. Abelson, E. Kaufman, M. Symer, et al., "Barriers and benefits to using mobile health technology after operation: A qualitative study," Surgery, vol. 162, no. 3, 2017.

[3] H. P. Profita, J. Clawson, S. Gilliland, et al., "Don't mind me touching my wrist," in ISWC, Zurich, 2013.

[4] D. M. Levine, S. R. Lipsitz, and J. A. Linder, "Trends in seniors' use of digital health technology in the united states, 2011-2014," JAMA, vol. 316, no. 5, p. 538, Aug. 2016.

[5] S. Mallenius and V. K. Tuunainen, "Factors affecting the adoption and use of mobile devices and services by elderly people - results from a pilot study," in Proceeding of 6th Annual Global Mobility Roundtable, 2007.

[6] X. Fafoutis, L. Clare, N. Grabham, et al., "Energy neutral activity monitoring: Wearables powered by smart inductive charging surfaces," in IEEE SECON, London, Jun. 2016.

[7] P. D. Mitcheson, E. M. Yeatman, G. K. Rao, et al., "Energy harvesting from human and machine motion for wireless electronic devices," Proc. IEEE, vol. 96, no. 9, pp. 14571486, 2008.

[8] H. Fu, K. Cao, R. Xu, et al., "Footstep energy harvesting using heel strike-induced airflow for human activity sensing," in IEEE Wearable and Implantable BSN, San Francisco, Jun. 2016.

[9] N. Shenck and J. Paradiso, "Energy scavenging with shoemounted piezoelectrics," IEEE Micro, vol. 21, no. 3, pp. 3042, 2001.

[10] D. Jarchi and A. J. Casson, "Estimation of heart rate from foot worn photoplethysmography sensors during fast bike exercise," in IEEE EMBC, Orlando, Aug. 2016.

[11] N. Hegde, T. Zhang, G. Uswatte, et al., "The pediatric SmartShoe: Wearable sensor system for ambulatory monitoring of physical activity and gait," IEEE Trans. Neural Syst. Rehab. Eng., vol. 26, no. 2, pp. 477-486, 2017.

[12] M. Gorlatova, J. Sarik, G. Grebla, et al., "Movers and shakers: Kinetic energy harvesting for the internet of things," IEEE J. Selected Areas in Comms., vol. 33, no. 8, pp. 16241639, 2015.

[13] G. Chen, E. Rodriguez-Villegas, and A. J. Casson, "Wearable algorithms: An overview of a truly multi-disciplinary problem," in Wearable Sensors, E. Sazonov and M. R. Neuman, Eds., Amsterdam: Elsevier, 2014, pp. 353-382.

[14] Nordic Semiconductor. (2016). nRF52 Online Power Profiler, [Online]. Available: https : / / devzone . nordicsemi.com/power/. 